\title{
A cannulated probe for torn inferior canaliculus repair
}

\author{
PETER T. C. DOCHERTY \\ From the Wolverhampton and Midland Counties Eye Infirmary
}

SUMMARY A cannulated probe and silicone tube for the repair of the torn inferior canaliculus are described and illustrated.

The repair of the torn inferior canaliculus (Fig. 1 $a$ and $b$ ) remains one of the ophthalmic surgeon's more tantalising problems, to which many approaches have been made. Among these are an ingenious method devised by D. P. Greaves (Stallard, 1976), using a lachrymal cannula and nylon thread, the retrograde needles of Kellnar (1960), the hooked pigtail probe from the Dutch Medical Workshop (Worst, 1962), the French eye pigtail probe (Kartch, 1971), and a method devised by Meacham (Meacham, 1972), using the Veirs rod (Veirs, 1962) and the pigtail probe (Worst, 1962).

The author has developed the lachrymal cannula a stage further and designed a cannulated probe (Fig. 2) with left and right-sided ends. Having introduced this instrument via the upper punctum and canaliculus until it presents at the torn medial end of the lower canaliculus or at the orifice of the lower punctum (Fig. 3), a length of silicone tubing, fused to a 4/0 nylon suture (Fig. 4) (CaudwellDocherty tube), is introduced into the probe (Fig. 5). It can be seen that when the silicone is homed into the tip of the probe (Fig. 6) the transition from probe to tubing is smooth and atraumatic to the delicate epithelium of the canaliculus. The probe is then withdrawn (Fig. 7).

Silicone tubing is the ideal material for intubation as it is sufficiently wide to re-establish the original canaliculus's internal diameter and, being flexible, is well tolerated strapped to the forehead for 4 weeks. It therefore increases the probability of successful reconstruction of the canaliculus.

The operating microscope and constant suction greatly facilitate the introduction and passage of the probe into the canalicular circuit, as the tip can

Address for reprints: Peter T. C. Docherty, FRCS, Wolverhampton and Midland Counties Eye Infirmary, Compton Road, Wolverhampton WV3 9QR

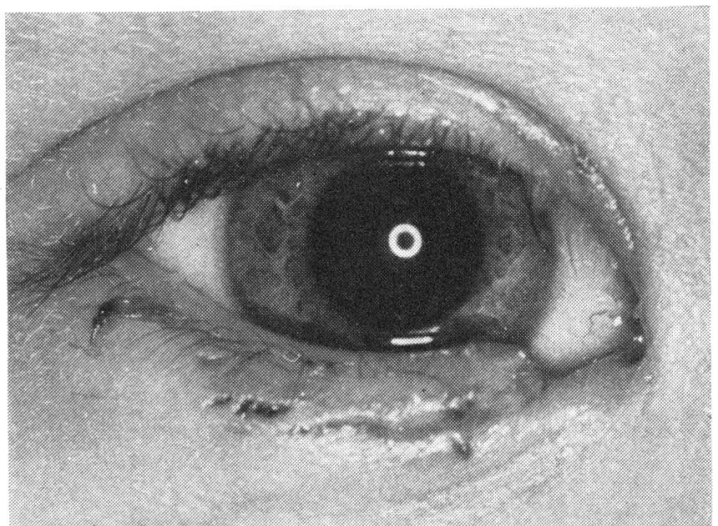

Fig. 1 a Torn inferior canaliculus

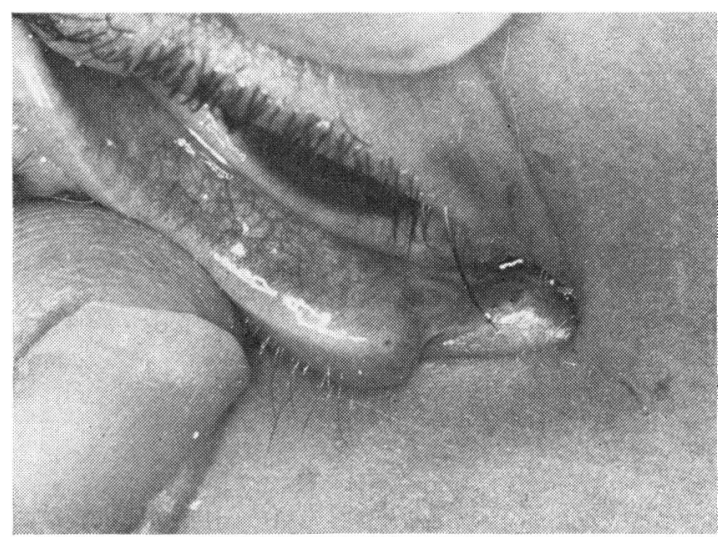

Fig. $1 b$

often be observed throughout its passage along the canaliculae.

Where the injury is restricted to the tissues near the torn canaliculus, $6 / 0$ collagen has been found most suitable for repairing both the subcutaneous 


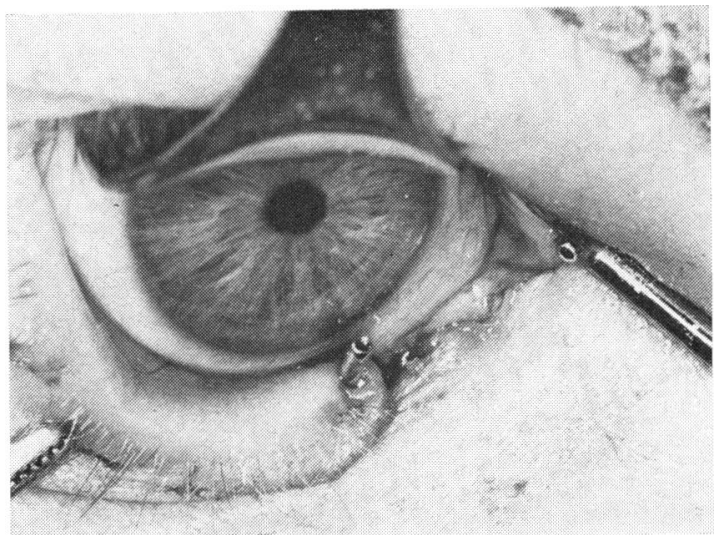

Fig. 3 Probe presenting at the lower punctum

Fig. 2 The Docherty cannulated probe

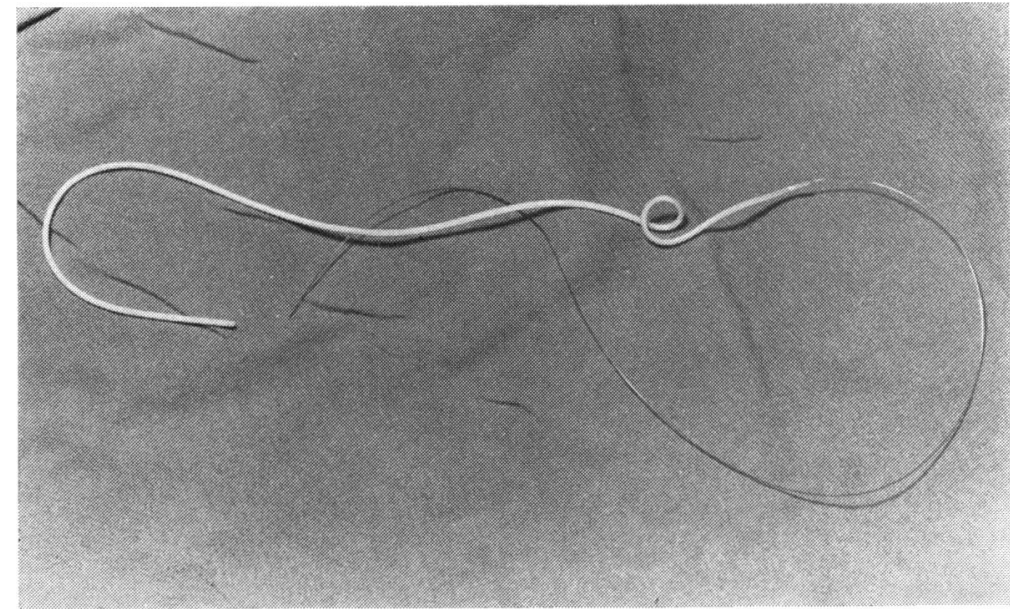

Fig. 4 The Caudwell-Docherty tube in the probe

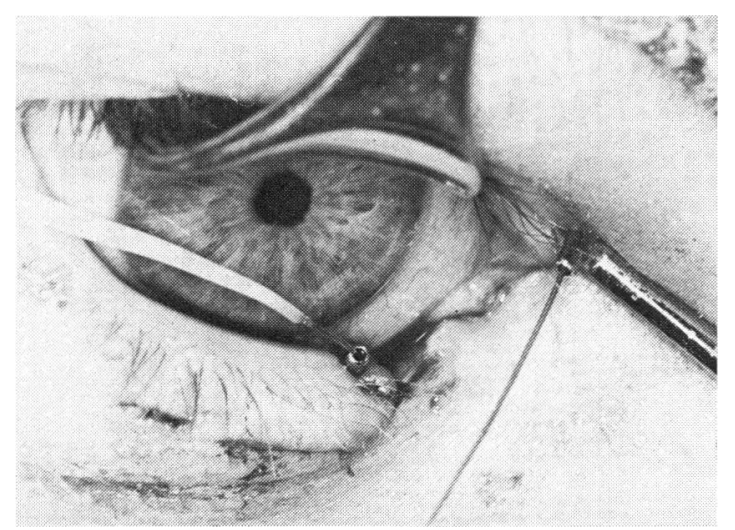

Fig. 5 Nylon portion of the Caudwell-Docherty tube in the probe

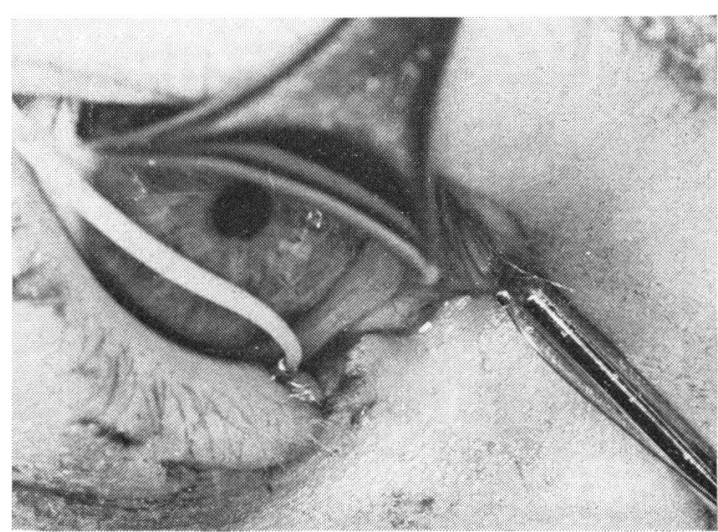

Fig. 6 Silicone tubing homing into the probe 


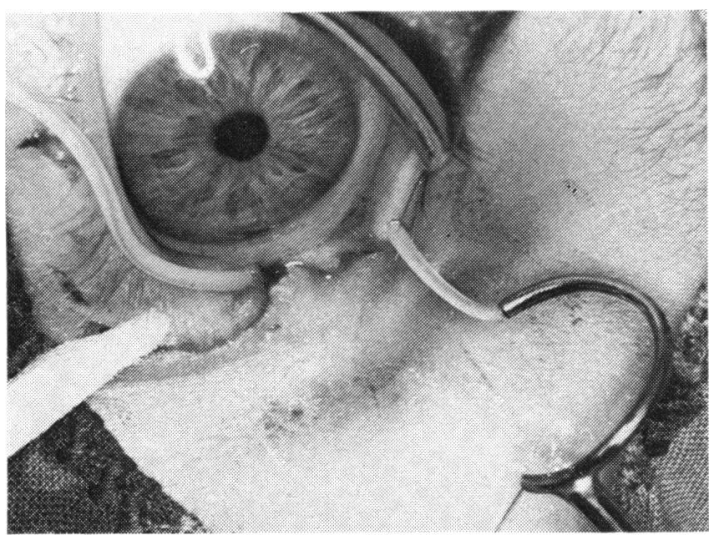

Fig. 7 Probe withdrawn

tissues and the skin, and it has the advantage, particularly in children, in whom this injury is common, of being absorbed. It also produces minimal suture scarring (Fig. 8).

I thank Mr Peter Caudwell, of the Medical Physics Unit at the Royal Hospital, Wolverhampton, for manufacturing the prototype of the instrument and devising the method of fusing silicone tubing to nylon; Mrs Helen Price, of the Department of Medical Photography of the same hospital, for the illustrations; and the staff at the Wolverhampton Eye Infirmary for their helpful advice.

The cannulated probe and silicone tubing are manufactured by Dixey \& Co Ltd.

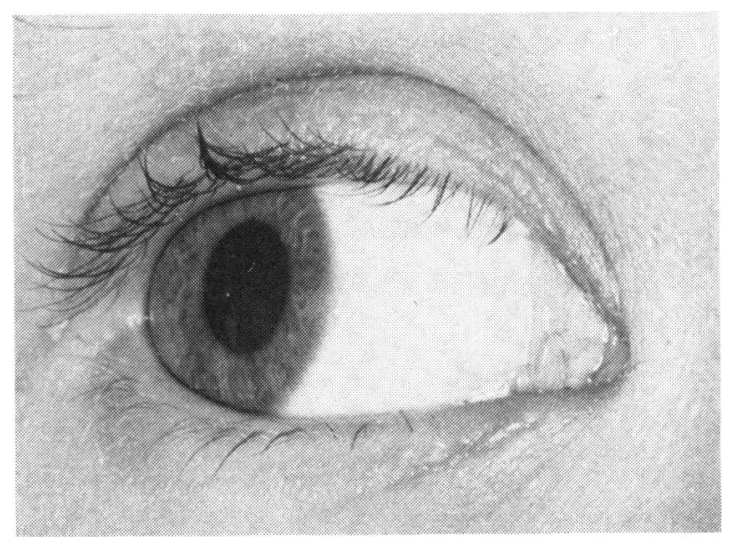

Fig. 8 Four weeks after original injury

\section{References}

Kartch, M. C. (1971). French eye pigtail probe for lacrimal canaliculus repair. American Journal of Ophthalmology, $72,1145-1146$.

Kellnar, W. (1960). The treatment of canalicular injuries with the help of a retrograde probe. Klinische Monatsblatter für Angenheilkunde, 137, 93-96.

Meacham, C. T. (1972). The hard to repair severed lacrimal canaliculus. Archives of Ophthalmology, 87, 406.

Stallard, H. B. (1976). Eye Surgery, 5th edn., p. 287, Wright: Bristol.

Veirs, E. R. (1962). Malleable rods for the immediate repair of the traumatically severed lacrimal canaliculus. Transactions of the American Academy of Ophthalmology and Otolaryngology, 66, 263-264.

Worst, J. G. F. (1962). Method for reconstructing torn lacrimal canaliculus. American Journal of Ophthalmology, $53,520-523$. 